\title{
Modeling and Simulation of DC Motor Speed Regulation by Field Current Control Using MATLAB
}

\author{
Rinita Rudra ${ }^{1 *}$, Rumrum Banerjee ${ }^{2}$ \\ ${ }^{1}$ Department of Electrical Engineering, Adamas Institute of Technology, Barasat, Kolkata, India. \\ 2 Department of Electrical Engineering, University of Engineering \& Management, Newtown, Kolkata, India. \\ * Corresponding author. Email: rinita_rudra@yahoo.com \\ Manuscript submitted July 10, 2017; accepted September 18, 2017. \\ doi: 10.17706/ijcee.2017.9.2.502-512
}

\begin{abstract}
Today's Technology requires faster and easier methods of controlling equipment. Direct Current (DC) motor is one of such equipment. Its speed is inversely proportional to flux, hence field current. Using this established relationship between the speed and flux, this paper investigates the effects of different field current on the output response of the field controlled direct current motor. The aim is to establish relationship between the speed of DC motor and the load torque at different field current. The first stage of the study involves mathematical modeling of the system while the second stage is based on the simulation of a field controlled DC motor in MATLAB SIMULATION environment. The steady state response shows that at different field current speed of the DC motor is directly proportional to the load torque. The transient response shows that without any feedback the performance of the response can be improved.
\end{abstract}

Key words: DC motor, field current, types of DC motor, different variables.

\section{Introduction}

In modern days several developments has been made to improve various parameters of electrical motoring systems. This alteration is not forever noticeable but the moment in time scale is long as skilled in a quantity of ecological progression. In technical field we concentrate mainly on time-dependent parameters. In ideal condition any entity or progression must contain suitable timing. This category of explanation is acknowledged as model.

Model is merely a depiction of the structure and functioning of some systems of concern. Fundamentally, a fine model is a sensible swapping between practicality and minimalism. One significant issues in modeling is model authority, which is the progression simulating the model underneath recognized input state of affairs and comparing model output by means of system output.

Simulation is the imitation of the operation of a real-world process or system over time. The act of simulating something first requires that a model be developed; this model represents the key characteristics or functions of the selected physical or abstract system or process. The model represents the system itself, whereas the simulation represents the operation of the system over time.

In this field controlled DC motor modeling, both the responses for step and impulse inputs have been investigated. On the basis of the modeled circuit, all the data has been analyzed on the basis of both MATLAB software as well as by calculation.

For proper understanding and clear visualization of this paper, the remaining parts of this paper are structured as follows. In Section 2, thorough information on DC motor (operating principle, classification, 
methods of speed control) is described. In Section 3, the detailing of model development for MATLAB simulation is provided. Simulation process and related discussion on the basis of result obtained is described in Section 5 Section 6 provides the conclusion part.

\section{Direct Current Motor}

It can be easily said that any electro-mechanical movements happens around us are caused either by an $\mathrm{AC}$ or a DC motor. In DC motor is one of oldest motor to convert electrical to mechanical energy.

This DC or direct current motor works on the principal, when a current carrying conductor is placed in a magnetic field, it experiences a torque and has a tendency to move. This is known as motoring action. If the direction of current in the wire is reversed, the direction of rotation also reverses. When magnetic field and electric field interact they produce a mechanical force, and based on that the working principle of DC motor is established [1].

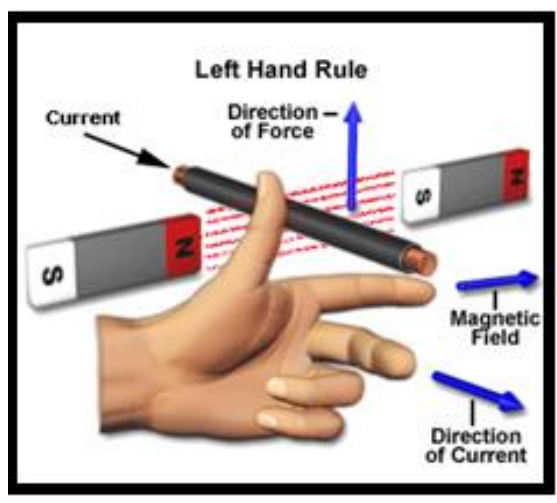

Fig. 1. Fleming's left hand rule.

The direction of rotation of a this motor is given by Fleming's left hand rule, which states that if the index finger, middle finger and thumb of your left hand are extended mutually perpendicular to each other and if the index finger represents the direction of magnetic field, middle finger indicates the direction of current, then the thumb represents the direction in which force is experienced by the shaft of the DC motor [1]. Fig.1 represents the Fleming's left-hand rule.

Structurally and construction wise a direct current motor is exactly similar to a DC generator, but electrically it is just the opposite. Here we unlike a generator we supply electrical energy to the input port and derive mechanical energy from the output port. We can represent it by the block diagram shown below.

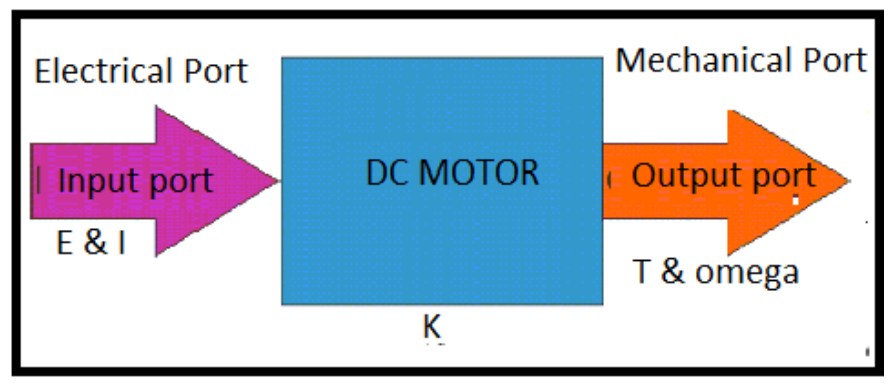

Fig. 2. Block representation of I/O module of DC motor.

Here in a DC motor, the supply voltage $E$ and current $I$ is given to the electrical port or the input port and we derive the mechanical output i.e. torque $T$ and speed $\omega$ from the mechanical port or output port. 
The input and output port variables of the direct current motor are related by the parameter $K$.

$$
T=K I \text { and } E=K \omega
$$

So from the picture above we can well understand that motor is just the opposite phenomena of a DC generator, and we can derive both motoring and generating operation from the same machine by simply reversing the ports.

From all the discussions we can simplify it as-

1. The developed electromagnetic torque produces (aids) rotation.

2. The voltage generated in the current-carrying conductors (counter-EMF) opposes the armature current (Lenz's Law).

3. The counter EMF may be expressed by the equation

$$
E_{e}=V_{a}-I_{a} R_{a}
$$

and is less than the applied voltage causing a given armature current flow $I_{a \text {. }}$

Equation (1) may be rewritten in terms of the armature current $I_{a}$ produced for a given applied voltage and load:

$$
I_{a}=\frac{V_{a}-E_{a}}{R_{a}}
$$

The magnitude and that are required to produce electromagnetic force on a given current-carrying armature conductor (a force orthogonal to $B$ and $I$ ) may be expressed by the Biot-Savart law in SI:

$$
F=\text { BIL newtons }(N)
$$

Finally, the direction of electromagnetic force developed by such a current-carrying conductor in a given magnetic field may be determined by the left-hand rule [2].

DC motor has several coils wound in the rotor part, now all these coils will experience force which creates torque in the motor. Due to these torque motor force to start rotating. If the amount of current is more then it creates greater magnetic field, then larger force will be created and motor starts moving with greater speed. In different position of movement of rotor, the linked flux will change and as a result it induces emf. This produced emf opposes the main voltage for which current is flowing through the conductor and it is known as back-emf of DC motor. Here, on point should remember that a small reduction in Back-emf can cause in a much greater increase in armature current. Similarly, slight changes in speed of the motor may accompanied by huge changes in motor current.

The back EMF of a motor may be written as-

$$
E=K^{\prime} \Phi \omega \text { volts }
$$

where, $\Phi$ is the field flux in lines or Weber

$\omega$ is the speed in $\mathrm{rad} / \mathrm{s}$

But, the back-emf of a motor, including volt drop across brushes or brush drop $(B D)$, is

$$
E_{e}=V_{a}-\left(I_{a} R_{a}+B D\right)
$$

Substituting the expression of back-emf of a motor, we get that 


$$
\omega=\frac{V_{a}-\left(I_{a} R_{a}+B D\right)}{k \Phi}
$$

where, all components are already defined.

Equation (6) is known as fundamental dc motor speed equation as it shows the dc motor performance at a glance. It can be said that if the field flux of a dc motor is weakened considerably, the motor will quit. From the equation it can be said if the denominator part approaches zero, the speed simultaneously reaches to infinity. Again, if load current and flux taken constant, with the voltage fascinated across the motor armature is increased. The amount of increasing speed will be in same proportion. The motor speed will drop in the same amount as with decreasing back-emf, when the field flux and the voltage across the armature are fixed. It is to be noted that the back-emf has decreased and, since speed varies directly with back emf. Similar way, if the flux has increased, but an increase in $\Phi$ creates decreases in speed [9].

\section{Field Flux Control Method of DC Motor}

Flux is produced by the field current, thus, the speed control by this method is achieved by control of the field current.

\subsection{Shunt Motor}

In a Shunt Motor, the variable resistor $R_{C}$ is connected in series with the shunt field windings as shown in the figure below. This resistor $R_{C}$ is known as a Shunt Field Regulator.

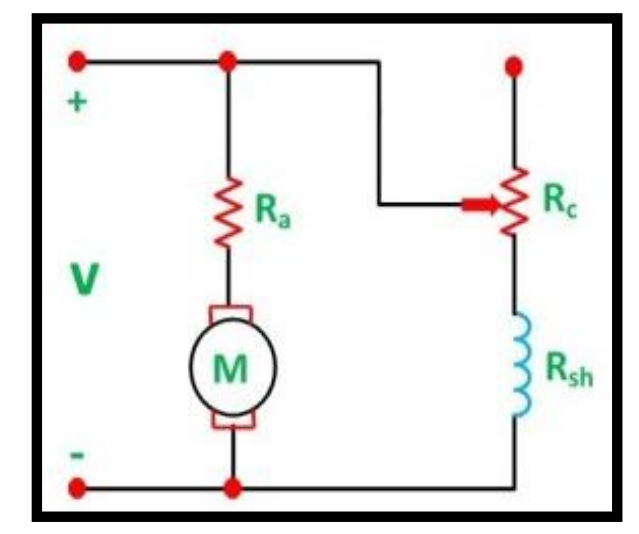

Fig. 3. Circuitry representation of DC shunt motor.

The shunt field current is given by the equation shown below.

$$
I_{s h}=\frac{V}{R_{s h}+R_{C}}
$$

The connection of $R_{C}$ in the field reduces the field current and hence the flux is also reduced. This reduction in flux increases the speed and thus, the motor runs at a speed higher than the normal speed. Therefore, this method is used to give motor speed above normal or to correct the fall of speed because of the load [14].

The speed-torque curve for shunt motor is shown below. 


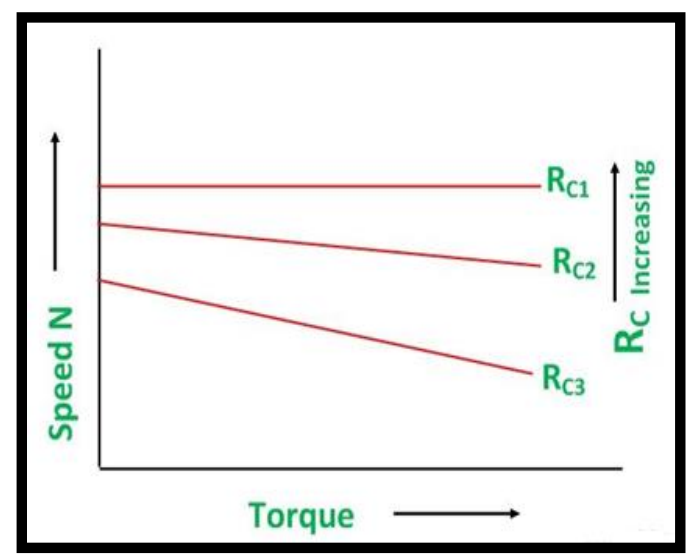

Fig 3.1. Torque-speed characteristics of DC shunt motor.

\subsection{Series Motor}

In a series motor, the variation in field current is done by any one method, i.e. either by a diverter or by a tapped field control.

\subsection{By Using a Diverter}

A variable resistance $R_{d}$ is connected in parallel with the series field windings as shown in the figure below.

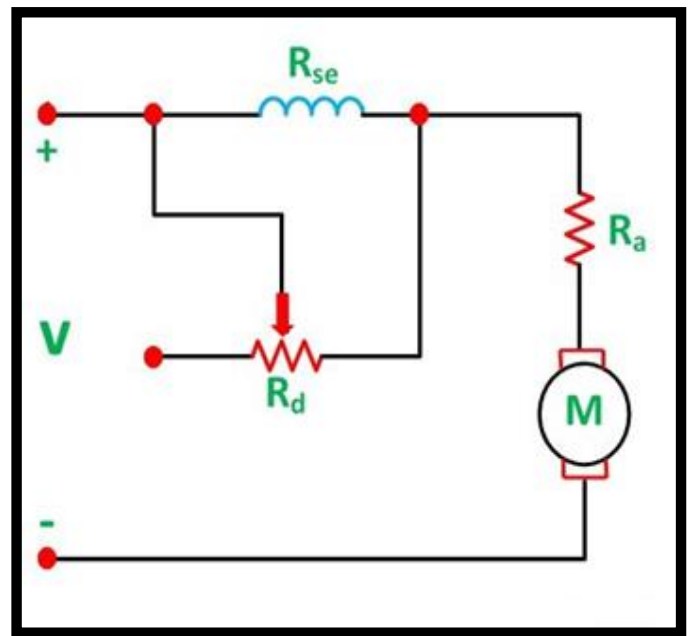

Fig 3.2. Variable resistance connection with series field winding.

The parallel resistor is called a Diverter. A portion of the main current is diverted through a variable resistance $R_{d}$. Thus, the function of a diverter is to reduce the current flowing through the field winding. The reduction in field current reduces the amount of flux and as a result the speed of the motor increases [3], [4].

\section{Model Development}

The field control of DC Motor study, will consider a simpler electrical circuitry of a DC motor as per Fig. 3. Different stages of control is represented hereby in the next section. 


\subsection{Representation Field Controlled DC Motor Circuit Diagram}

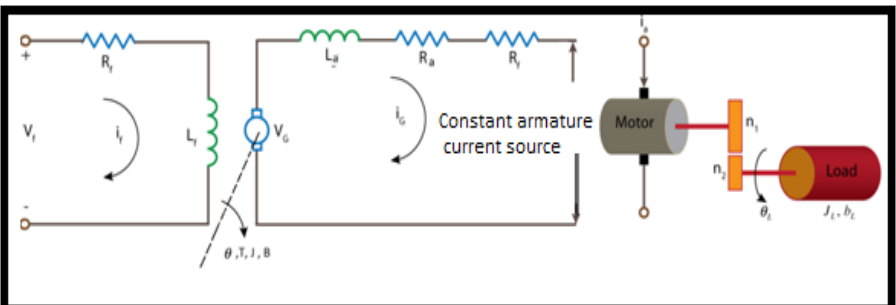

Fig. 4. Field-controlled DC motor.

Here, a constant current $I_{a}$ is fed as the armature current. As per theory we can say flux is directly proportional to the field current [10]-[14].

$$
\begin{gathered}
\theta \infty I_{f} \\
\theta=K_{f} I_{f}
\end{gathered}
$$

Apply KVL in field circuit

$$
V_{f}=R_{f} I_{f}+L_{f} \frac{d I_{f}}{d t}
$$

Torque developed by the motor is proportional to the flux and armature current

$$
T \infty \theta I_{a}
$$

From equation 4.1 we can write that-

$$
\begin{gathered}
\mathrm{T}=\mathrm{K}^{\prime} \mathrm{K}_{\mathrm{f}} \mathrm{I}_{\mathrm{a}} \mathrm{I}_{\mathrm{f}} \\
\mathrm{T}=\mathrm{K} \mathrm{K}_{\mathrm{f}} \mathrm{I}_{\mathrm{f}} \text { where } \mathrm{K}=\mathrm{K}^{\prime} \mathrm{I}_{\mathrm{a}}
\end{gathered}
$$

We know from dynamic equation of torque in forms of $\mathrm{J}$ and $\mathrm{B}$

$$
T=J \frac{d^{2} \theta}{d t^{2}}+B \frac{d \theta}{d t}
$$

If we do Laplace transformation of equation (4.3), (4.4), (4.5) we can get,

$$
\begin{aligned}
V_{f}(s)=R_{f} I_{f}(s)+s L_{f} I_{f}(s) & =I_{f}(s)\left[R_{f}+s L_{f}\right] \quad I_{f}(\mathrm{~s})=\frac{V_{f}(s)}{R_{f}+s L_{f}} \\
\mathrm{~T}(\mathrm{~s}) & =\mathrm{K} \mathrm{K}_{\mathrm{f}} \mathrm{I}_{\mathrm{f}}(\mathrm{s}) \\
\mathrm{T}(\mathrm{s}) & =\theta(\mathrm{s})\left[\mathrm{S}^{2} \mathrm{~J}+\mathrm{sB}\right]
\end{aligned}
$$

After putting the value of $I_{f}(s)$ from equation (3.6)-(3.8) 


$$
\mathrm{T}(\mathrm{s})=\mathrm{K} \cdot \mathrm{K}_{\mathrm{f}} \frac{V_{f}(s)}{R_{f}+s L_{f}}
$$

From equations (3.8) and (3.9)

$$
\begin{gathered}
\theta(\mathrm{s})\left[\mathrm{S}^{2} \mathrm{~J}+\mathrm{sB}\right]=\mathrm{K} . \mathrm{K}_{\mathrm{f} .} \\
\frac{\theta(s)}{V_{f}(s)}=\frac{K K_{f}}{s(s J+B)\left(R_{f}+s L_{f}\right)}
\end{gathered}
$$

From equation (4.10) can be written as

$$
\frac{\theta(s)}{V_{f}(s)}=\frac{K K_{f}}{R_{f} B s\left(1+s \frac{J}{B}\right)\left(1+s \frac{L_{f}}{R_{f}}\right)}=\frac{K K_{f}}{R_{f} B s\left(1+s \tau_{m}\right)\left(1+s \tau_{f}\right)}
$$

where $\tau_{m}=\frac{J}{B}=$ mechanical time constant

$\tau_{f}=\frac{L_{f}}{R_{f}}=$ time constant for field circuit

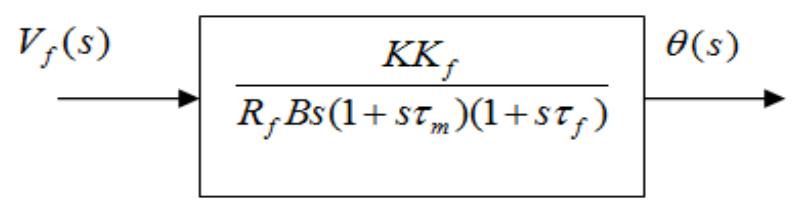

Fig. 4.1. Block diagram of field controlled dc motor.

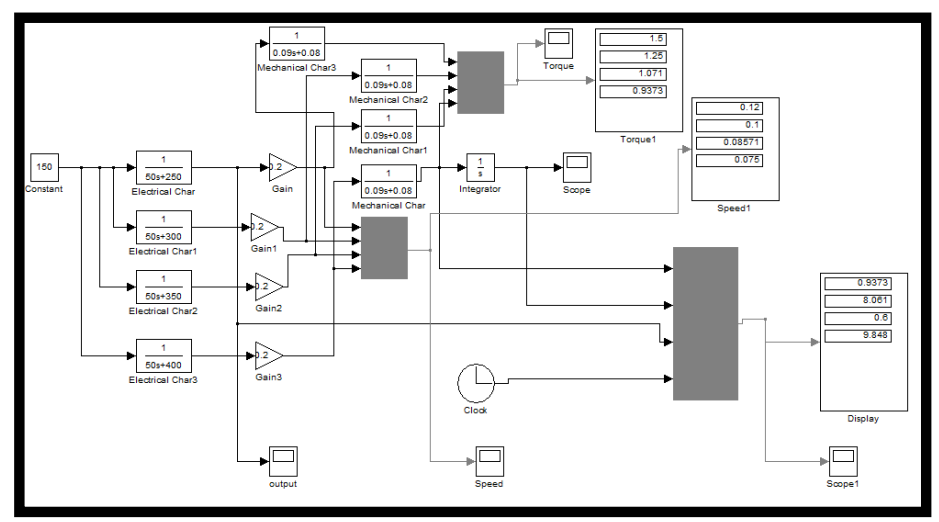

Fig. 5. Model created in SIMULINK toolbox of MATLAB.

\section{Simulations Results and Discussions}

The simulation was done as well as analyzed based on its transient and steady state responses. For transient response, the standard test signals were step and impulse functions. The motor specifications are: $3 \mathrm{hp}, 150 \mathrm{~V}$ and $1500 \mathrm{rpm}$, the other parameters are:

$$
\mathrm{R}_{\mathrm{f}}=250 \Omega, \mathrm{L}_{\mathrm{f}}=50 \mathrm{H}, \mathrm{J}=0.09 \mathrm{kgm}, \mathrm{B}=0.08 \mathrm{Nmrad}^{-1} \mathrm{~s}^{-1}, \mathrm{kk}_{\mathrm{f}}=0.2 \text {. }
$$

As, for this analysis all the initial conditions are assumed to be zero. So, at the time of starting, there is no 
current flowing through the motor. Below sub-sections represent the results under steady state and transient conditions, assuming the above values as inputs.

\subsection{Steady State Response}

The steady state responses of this field controlled DC motor show the operating characteristics of the motor under different conditions. The steady state responses under consideration are: field current speed characteristics and torque speed characteristic for different field current [6]-[8].

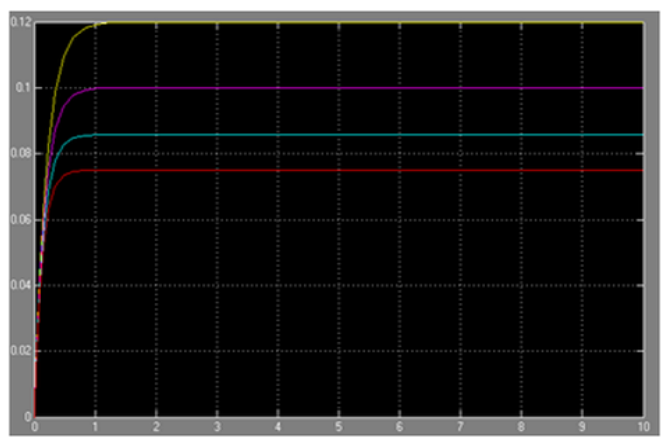

Fig. 6. Plot of the field current against motor speed.

The Steady state response curve in Fig. 6 shows the variation in the speed as the field current decreases. The result shows that the speed increases as field current is decreased. This implies the well known fact that the speed is inversely proportional to flux produced.

At different field current, the variation of the torque speed characteristics for the dc motor under steady state condition was obtained. The result is shown in Fig. 7. This figure implies that, at different field current, the higher the speed the higher the load torque. Hence, speed of the dc motor at different field current is directly proportional to the load torque [15].

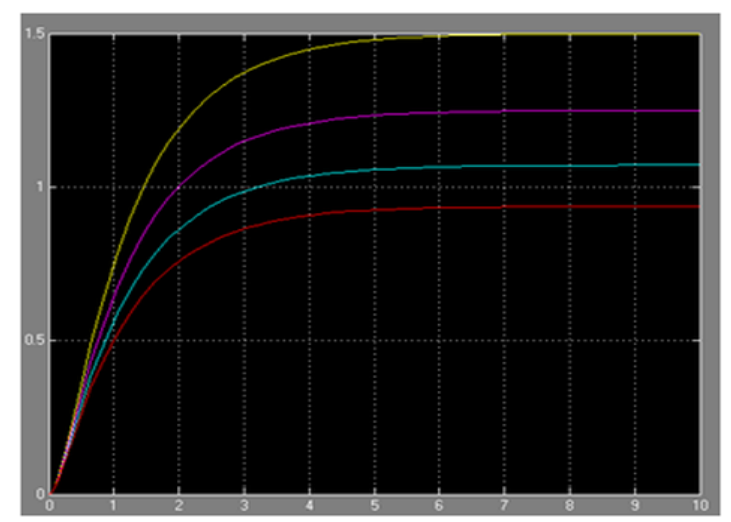

Fig. 7. Torque-speed characteristic for different field current.

\subsection{Transient Response}

In a similar way, the transient response of the modeled field controlled DC motor was examined. In the proposed model, as there is no feedback loop, so variation of $\mathrm{kk}_{\mathrm{f}}$ remains ineffective on the stability or performance of the motor, except the amplitude of the output increases. But one important thing is that, as the value of $k k_{f}$ increases, the amplitude of the speed curve decreases, and it reaches to steady state stability more quickly. Fig. $8-10$ shows the responses of the motor for $k k_{f}=0.2,0.8$ and 1.5 respectively. 


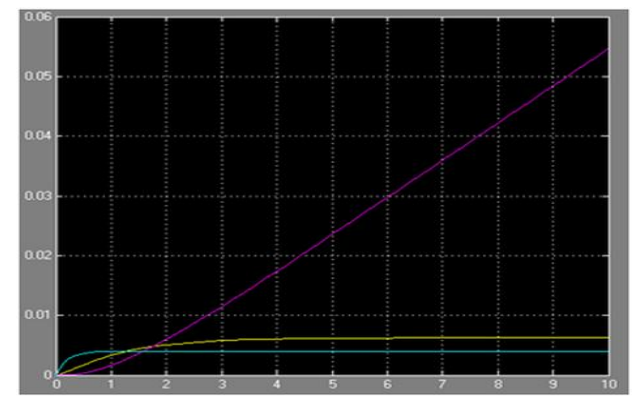

Fig. 8. Responses of the motor to a unit step input at $k k f=0.2$.

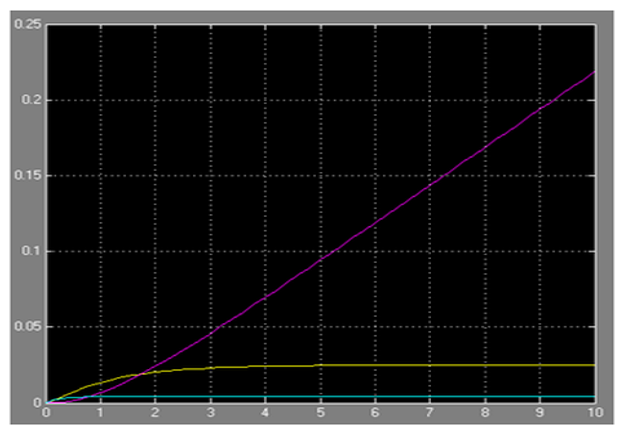

Fig. 9. Responses of the motor to a unit step input at $k k_{f}=0.8$.

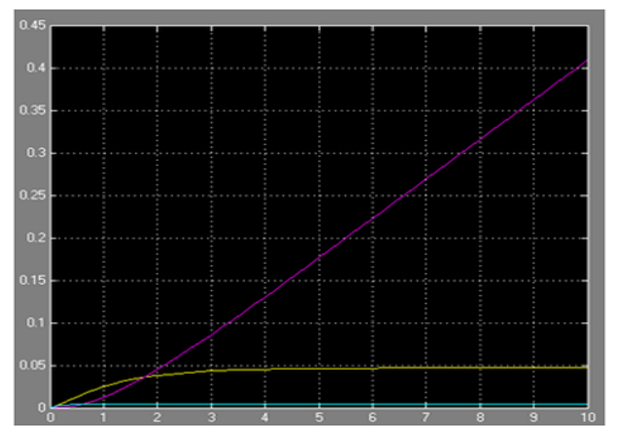

Fig. 10. Responses of the motor to a unit step input at $k k_{f}=1.5$.

Besides the step response, the impulse response of the motor was also examined at different values of $k k_{f}$. The responses are shown in Fig. 11-13.The graphs obtained for different values of $\mathrm{kk}_{\mathrm{f}}$ are almost similar in nature except that the time units are different to return to zero. Similar to step response, here also, as the value of $\mathrm{kk}_{\mathrm{f}}$ increases, the amplitude of the speed curve decreases, and it reaches to stability more quickly.

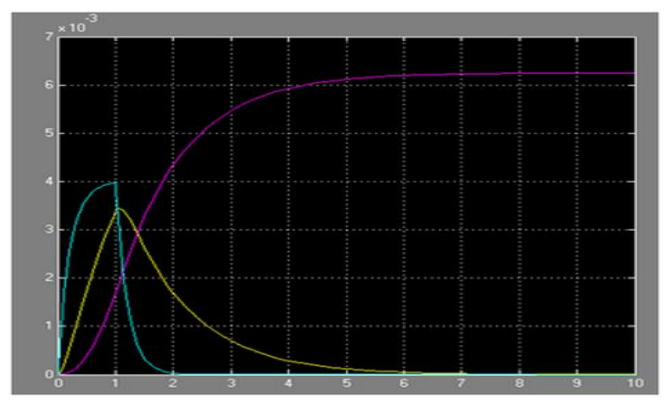

Fig. 11. Responses of the motor to an impulse input at $\mathrm{kk}_{\mathrm{f}}=0.2$. 


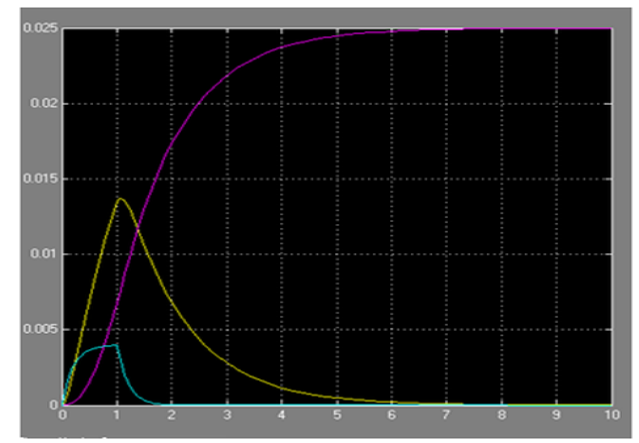

Fig. 12.Responses of the motor to an impulse input at $\mathrm{kk}_{\mathrm{f}}=0.8$.

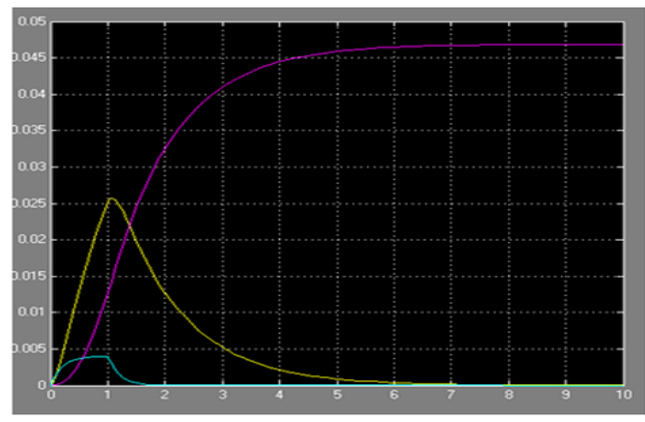

Fig. 13. Responses of the motor to an impulse input at $\mathrm{kk}_{\mathrm{f}}=1.5$.

The speed of the motor at different values of $k k_{f}$ was observed and is has been investigated that whether it affects the stability of the motor. From the results obtained, it can be concluded that, speed of the motor is inversely proportional to the value of $k k_{f}$.

\section{Conclusion}

The discussion has made in this paper about field controlled Dc Motor in MATLAB-SIMULATION environment. The various graphical analytical results shows that the motor accurately defining the effect of change in filed current in the field current vs. speed characteristics curve as well as torque vs. speed curve of the designed field controlled DC motor. Also it can be said in addition to that is the steady state response shows that at different field current speed of the DC motor is directly proportional to the load torque. The transient response shows that without any feedback the performance of the response can also be improved.

\section{References}

[1] Jide Julius, P., Oladele Joshua, O., \& Charity Segun, O. (2015). Modelling and simulation of armature controlled direct current motor using MATLAB. SSRG International Journal of Electrical and Electronics Engineering (SSRG-IJEEE), 2(3), 19-25.

[2] Bansal, D., Evans, D. J., \& Jones, B. (2004). A realtime predictive maintenance system for machine systems. International Journal of Machine Tools \& Manufacture, 44, 759-766.

[3] Nandam, P. K., \& Sen, P. C. (1986). A comparative study of proportional-integral (P-I) and integralproportional (I-P) controllers for dc motor drives. Int. Jour. Of Control, 44, 283-297.

[4] George, M., Basu, K. P., \& Chiat, A. T. W. (2010). Model reference controlled separately excited DC motor. Neural Computing and Applications, 19, 343-351.

[5] Gaurav Kumar, M., Pandey, A. K., \& Avinash, M. (2014). Combined armature and field speed control of DC motor for efficiency enhancement. SSRG International Journal of Electrical and Electronics 
Engineering (SSRG-IJEEE), 1(6).

[6] Anurag, D. (2013). Speed control of Dc shunt motor with field and armature rheostat control simultaneously. Advance in Electronic and Electric Engineering, 3(1), 77-80.

[7] Moleykutty, G. Speed control of separately excited DC motor. American Journal of Applied Sciences, 5(3), 227233.

[8] Monaaf, D. A. A. Speed control of a separately-excited DC motor. International Journal of Research in Aeronautical and Mechanical Engineering.

[9] Kosow. Electric Machinery and Transformers. Pearson Education India.

[10] Krisnan, R. (2011). Electric Motor Drives: Modeling, Analysis, and Control. New York: Prentice Hall.

[11] Hasan Saeed, S. Automatic Control Systems. S. K Kataria \& Sons.

[12] Roy Choudhury, D. Modern Control System. PHI Publications.

[13] DC motor or direct current motor. Electrical4u. Retrieved from http://www.electrical4u.com/dcmotor-or-direct-current-motor/

[14] Speed control of DC motor: Armature resistance control and field flux control. Circuitglobe. Retrieved from http://circuitglobe.com/speed-control-of-dc-motor-armature-resistance-control-and-field-fluxcontrol.html

[15] Rajeshkanna, G. (2013). Modern speed control of separately excited DC motor by boost converter fed field control method. Proceedings of 2013 International Conference on Computer Communication and Informatics (ICCCI).

Rinita Rudra is an assistant professor of Electrical Engineering Department at Adamas Institute of Technology (Barasat, Kolkata) under Moulana Abul Kalam University of Technology, West Bengal(MAKAUT). Her area of interests are electrical drives \& control system and also design of various controllers for electrical drives.

She is M.Tech from Calcutta University, Kolkata in electrical engineering and B.Tech in electrical engineering from WBUT (Presently known as MAKAUT).

Asst. Prof. Rinita has about 8 years teaching experience and two years of research experience. She has more than two research papers national level journal and conferences.

Rumrum Banerjee is an assistant professor of Electrical Engineering Department in University of Engineering \& Management, Kolkata. Her areas of interest include control system \& electrical machines and modulation of various functions in discrete domain.

She is M.Tech from Indian Institute of Technology, Kharagpur specialization in Electrical Engineering (Control System) and B.Tech in Electrical Engineering from WBUT (Presently known as MAKAUT).

Asst. Prof. Rumrum has more than 8 years teaching experience and one year of industrial experience. She is actively involved in various research works and students project work. 